\title{
THE SUBJECTIVE ASSESSMENT OF PAIN DURING THE TREATMENT OF ORTHOPAEDIC JOINT PROBLEMS
}

\author{
J. EDELING, B.Sc. Physiotherapy (Rand)*
}

\section{SUMMARY}

A system is proposed whereby the pain syndrome may be numerically expressed. The system was developed for the assessment of conditions where pain was the dominant clinical feature and objective findings were minimal e.g. headaches derived from the cervical spine. $A$ comprehensive subjective account of pain is recorded and three of the variables are numerically graded to reflect the severity of the total syndrome. An example is given in order to demonstrate the clinical use of the system.

)

In the examination of any physical disorder the practitioner tries to reconcile subjective information with objective findings. If the condition involves the locomotive parts, the physiotherapist will try to define the problem in terms of joint or muscle dysfunction. Often the exact nature of the pathology has not been defined, and then trial treatment will be directed at effecting an improvement in signs and symptoms (Maitland, 1977). More weight is usually afforded to the signs, or objective findings, because they are more readily measurable and therefore of more scientific value.

In cases where the subjective and the objective examination are not equally informative the physiotherapist is obliged to depend largely, and at times totally, on the one or the other. In such cases it will be clear that more time and attention must be given to extricating every possible bit of information from the sources available.

Physiotherapists are often confronted with this situation in cases where the overriding complaint is that of pain. The underlying pathology may be of a degenerative nature, such as osteoarthritis and so we do not aim to arrest or cure it but direct our efforts to relieving the aspect of the pathology that bothers the patient and that is usually pain.

In such conditions pain is usually accompanied by stiffness or limitation of physiological movement (that thich a patient can perform actively) and/or accessory movement (that movement which cannot be performed actively). When this is so, measurement of the restriction forms an important part of the objective examination and the measured improvement in movement is used to evaluate the effectiveness of the trial treatment (Maitland, 1977).

Not infrequently there are patients who complain of severe pain, yet there is no measurable limitation of physiological movement. There is, in these cases, painful limitation of a particular accessory movement. This accessory movement might possibly be used as a treatment technique, but in the author's experience it is not a very useful objective finding for the purposes of reassessment.

If, therefore, physiotherapists are to have any chance of therapeutically relieving the pain in such cases they must make full use of all the available information (Maitland, 1978), including the patient's subjective account of pain. Many practitioners do not consider a subjective report of pain of much scientific value because it is not considered to be measurable. But when it becomes the only indicator, ways must be found to

* Yrivate practitioner, Johannesburg.

Received 19 April 1979.

\section{OPSOMMING}

'n Stelsel waarvolgens 'n pynsindroom numeries uitgedruk kan word, word voorgestel. Die stelsel is ontwikkel om toestande waar pyn die oorheersende kliniese teken en objektiewe bevindings minimaal was, byvoorbeeld hoofpyne afkomstig van die servikale gebied, te evalueer. 'n Omvattende subjektiewe verslag van pyn word opgeteken en drie variante word numeries gegradeer om die felheid van die gehele sindroom te weerspieël. 'n Voorbeeld word gegee om die kliniese aanwending van die stelsel te demonstreer.

use it. Review of the literature pertaining to the field of pain and information obtained on this score from treating over a thousand patients with headaches has led the author to establish a system for the subjective assessment of pain whereby comparable parameters are recorded. This system has proved to be helpful and dependable.

It is necessary to elicit and record a total pain pattern (T.P.P.) at first interview which includes a retrospective pattern starting, perhaps, years before and leading up to the pattern currently present. The T.P.P. is unique to each patient.

\section{GUIDING PRINCIPLES}

1. The recording of the T.P.P. will not necessarily lead to a diagnosis, although some of the clinical features might suggest specific pathology. In such cases it may be desirable to return the patient to the referring doctor for possible further investigation.

2. The purpose of recording a T.P.P. is to have a standard for comparison after treatment. In this way it will be possible to detect early marginal changes and so be able to evaluate the effectiveness of trial treatment.

3. There is admittedly no reliable way of comparing the subjective intensity of one person's pain with that of another. A patient is, however, well able to compare the intensity of her* own pain at different times. The patient's report of the varying intensities and the presence and absence of her own pain are recorded for later comparison. Every other clinical feature that can be extracted is also recorded. Many of these clinical features can be used as additional or alternate reassessment points.

4. The T.P.P., if adequately taken, will portray the increasing severity of the pain syndrome up to presentation, the initial response to treatment and the steady decrease until discharge. It will also enable the physiotherapist to judge to what extent the improvement is maintained at subsequent follow-up assessment.

5 . If the record is incomplete, attempts at reassessment are likely to be confusing and misleading.

TOTAL PAIN PATTERN (T.P.P.)

\section{Distribution}

The patient should be asked to indicate, using a

* The patjent will be referred to as she, her etc. for convenience. 
finger, the area of the worst pain, the extent and manner of radiation and any other related or unrelated areas of pain; also where the pain usually begins. The patient might say that under certain circumstances it is in one area and under others, elsewhere. These areas should be carefully drawn in on a chart with suitable annotations and, before going further, the patient should be shown the chart and requested to confirm the pain distribution recorded and to check notes for accuracy (see diagram 1). Changes in the pain distribution pattern could mean that treatment is having an effect on the pain.

\section{Nature of Pain}

A clear distinction must be made between the nature (or quality) of pain and the intensity of pain. If the question is put as follows:- "What does the pain feel like?" the patient will often tell how severe it is. It is better to ask "What does your pain feel like?" and add "I don't mean how bad it is but what sort of pain is it?" If a spontaneous reply is not forthcoming, she should be helped by saying: "Does it throb, or is there a feeling of pressure or burning with it?". and she will then cinderstand" and respond by saying: "Oh no it never ttirobs or burns - it's just a gnawing pain" or whatever the case may be. Some patients do not know that there are various qualities to pain. They think what they feel is pain and that all pain feels the way their's does.

\section{Periodicity (P)}

When there is an established periodicity pattern to the occurrence of pain this forms the most useful feature for measuring improvement. Mostly it is a very simple matter. If a patient has had a continuous pain for a long period and during the course of treatment the pain becomes intermittent and finally abates, one need not perform mental gymnastics in order to assess improvement.

All too often there are, however, confusing factors that bedevil assessment. This may cause one to abandon the only effective treatment because one had not been aware of the initial marginal improvement in the periodicity pattern.

It is useful to grade the periodicity from P1 - P5:

Grade $\mathrm{P} 1=$ Pain on one day a month or less.

$\mathbf{P 2}=$ Pain on two or more days per month.

P3 = Pain on one or more days a week.

P4 = Intermittent but daily pain.

P5 $=$ Continuous pain.

\section{Reassessment}

If a P5 pain abates altogether for even a very short while after treatment, it is no longer a P5 but a P4. If a P4 pain skips a day, this is an improvement, etc Where pain periodicity patterns do not readily con? form to this system because they are erratic, one is still able to use them but it requires much more skill.

\section{Intensity (I)}

Grade the subjective intensity of pain also from 1 - 5:

Grade $\mathbf{L}=$ Mild pain.

$\mathbf{I} 2=$ More than mild pain but tolerable.

I3 $=$ Moderately severe.

$\mathrm{I} 4=$ Severe.

$\mathbf{I 5}=$ Intolerable, suicidal pain.

Patients are often quick to match their pain intensity to one of the above grades. If they are not. they should

\section{PAIN DISTRIBUTION}

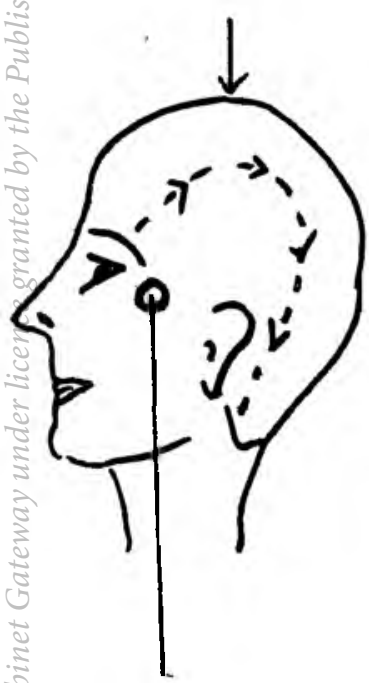

Very seldom on left same distribution never as severe
Feeling of pressure here at times
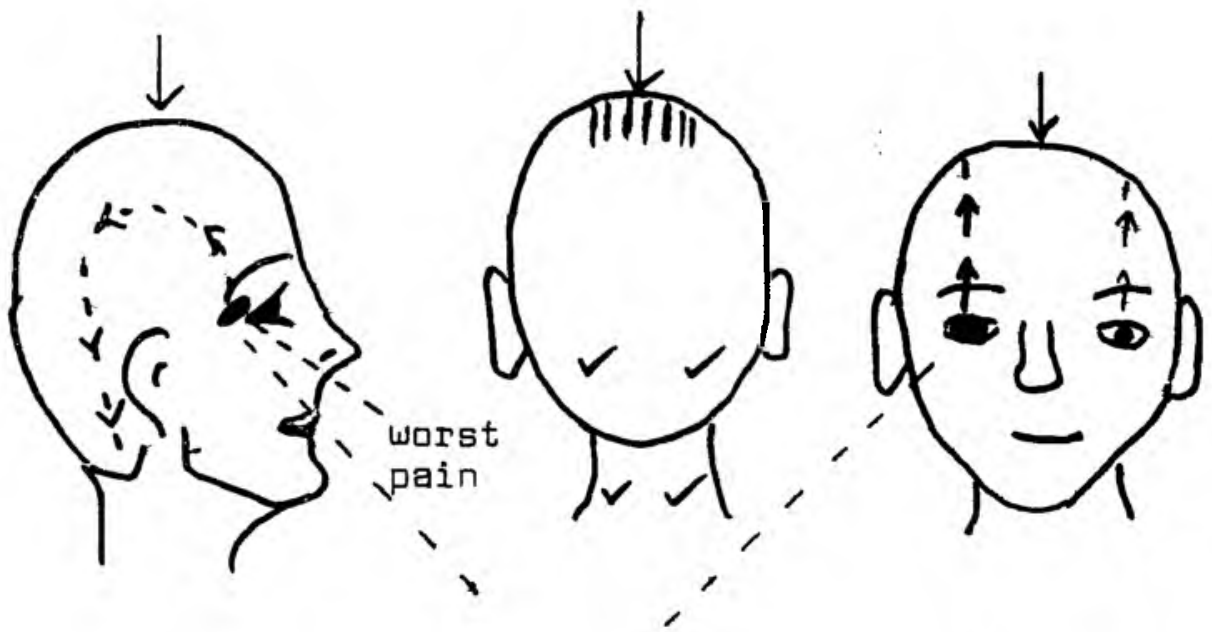

Starts here behind right eye moves up and backwards 
be asked what they feel like and how it affects them when the pain is at its worst. This usually unleashes a vivid description of the impact of the pain on the individual. The physiotherapist must then interpret this impact:

I1. Does the patient consider it to be "normal" pain? This is a pain that is acceptable to a person and that has no emotional overlay.

I3. Is the pain affecting the patient's life? Does it interrupt life style, work, domestic or social life?

15. Is the pain completely intolerable and disruptive? Is life totally engulfed in unrelieved, severe pain? Are there hints of suicide? Could you, the therapist, live with such pain?

Assess accordingly. Do you consider this pain to be Grade I1, I3 or I5 or in between I2 or I4? This is the physiotherapist's "measure" of the intensity of pain.

\section{Response to Analgesics}

(Self-administered or prescribed).

It seems that the response of pain to analgesia often depends on the stage of the pathology which is producing the pain. It also depends on the severity of the pain. If one considers the kind of pain which arises from painful joint restriction, it will be found that as the joint condition deteriorates, analgesics become progressively less effective. Later, if the physiotherapy treatment is improving the condition of the joint, analgesics seem to become more effective. As this fact emerged repeatedly in patients' reports, it was included in the system as another parameter for "measuring" the improvement of painful conditions. Very often assessment of the response to analgesics is helpful when reassessment of other factors is inconclusive.

For example, if initially a patient reports that no amount of analgesics totally relieves her pain but 2 Stopain will lessen it for an hour or so and after a couple of trial treatments she tells you that her pain went away completely for several hours with the same dose, this indicates an improvement. Response to analgesics may also be graded, R1 - R5:

Grade $R 1=$ Pain abates readily with small dose of mild analgesic.

R2 = Pain is lessened but does not abate with mild analgesic.

R3 = Pain is totally relieved by strong analgesic.

$\mathrm{R} 4$ = Pain is lessened but does not abate with large dose of strong analgesic.

RS = No dose of any analgesic even lessens the pain.

\section{Precipitating and Aggravating Factors}

In this instance the physiotherapist wishes to know from the patient what brings on a pain or makes a continuous pain worse.

When there is a spontaneous reply it should be recorded verbatim and earmarked for later comparison. If one or more of these factors become impotent after treatment, this signifies improvement in or cure of the pain-producing condition.

It will be found that the patient with a long established pattern of pain will readily supply these factors. Those with patterns of more recent onset will be less able to do so.

If a patient says she doesn't know that brings on her pain, she should be gently probed and given examples of the factors that many other patients report. This will make her think about it and she may be able to supply such information at her next visit. Sometimes, however, there is no discernable trigger factor.

\section{Associated or Concomitant Symptoms}

The patient should be asked: "Apart from the pain, do you have any other sensations that seem to be related to the pain?" These must be recorded verbatim. If she says she hears a sound in her left ear like a cricket, or bubbles, these should not be transcribed as "tinnitus". Record as said by the patient. Associated symptoms are less useful as a yardstick for improvement but the T.P.P. is incomplete if you do not know all about them. It is here that warnings of pathology which may lie beyond the scope of physiotherapy may be recognised. These replies should be recorded with the necessary attention. Sometimes these factors decrease before the pain does in which case they may be ndicative of improvement.

\section{History}

To complete the T.P.P., take a retrospective history which should cover aspects such as the following:

1. Initial onset of this pain pattern.

2. Progression over years/months/days.

3. Aetiology - whether trauma, disease, strain, surgery, pregnancy, occupational posture etc.

4. Previous treatment and response to it.

5. Familial factors.

\section{QUESTIONING TECHNIQUE}

1. Allow plenty of time for the first interview, about 45 minutes.

2. Use record sheets with standard headings to achieve an ordered pattern, but do not be rigid if the patient offers information that doesn't seem to fit the form. Record it under a heading called "miscellaneous" or "points of interest".

3. Do not restrict the patient to brief answers. Encourage her, at some stage, to just "tell me about your pain". This elicits a useful impression of just how much the pain intrudes upon her life. If she rambles on too much, she should be guided back to answering more direct questions.

4. Often patients are embarrassed about describing bizarre symptoms. They are afraid that the interviewer will think that they are imagining things or exaggerating. The physiotherapist should seem interested but unalarmed when they confide these "dark secrets" and reassure where necessary.

5. The physiotherapist should not seem to be censorious when asking about analgesics or other drugs. The patient will think that the physiotherapist is going to restrict her drug taking and will give evasive answers. She is already worried about side-effects but cannot face the pain without analgesics. She must be given to understand that all that is required is information for later comparison. If, later, she needs less by way of pain killers, her pain producing condition is improving. Also, if the same analgesic which previously gave no or little relief later gives some or total relief, the condition is improving.

6. When asking about aggravating or precipitating factors and/or associated symptoms the physiotherapist must be matter of fact. Patients with a chronic headache, for instance, frequently have concomitant symptoms that terrify them. "Strange noises in my ears" (tinnitus) or a constrictive or obstructive feeling in the throat (globulus hystericus), dysphasia and visual disturbances are but a few of these symptoms. These symptoms should be asked for in an ordinary sort of way, recorded, and the patient should be reassured if she seems 
anxious. If the patient says "you probably won't believe me but my pain is worst when my motherin-law visits", believe her and record this fact. If later in the course of treatment she reports a visit from mother-in-law with no ensuing headache, the physiotherapist may assume that it is the condition that has improved, not the mother-in-law! If you are alerted by a report, do not alarm the patient but make a note to check the following:

Is this a familiar report in the clinical situation or the literature? If so, was it indicative of something that lies within the scope of physiotherapy?

Has the patient told her doctor about it? Whether she has or not, it might be wise for the physiotherapist to discuss it with the doctor before proceeding with further treatment.

- Has the patient been seen by an appropriate specialist and have the necessary objective diagnostic procedures been executed? If so, there is seldom cause for alarm.

7. It is often helpful to record, verbatim, descriptive words or phrases used by the patient. These should not be transcribed. When reassessing at a later date use the word or phrase which was recorded at the first visit. This enables the patient to identify the sensation which she originally described. She will at once be able to compare her present sensations or pain reliably and to say, quite definitely, "I no longer have that dreadful scalding pain, it's just a dull ache now" etc.

8. If the patient finds a question difficult to answer, do not press her. Help her by:

Re-phrasing the question.

Telling her what you, as therapist, are seeking to establish.

Saying it needn't be exact but approximate.

Passing on to the next question, saying it is not important.

9. If the patient, at the first visit, is in severe pain do not subject her to prolonged questioning. Endeavour to obtain sufficient information to suggest a form of palliative treatment and leave the T.P.P. till the severe attack has passed.

10. When questioning for response to treatment never seem to be disappointed or sceptical when a patient reports a negative response. She should be questioned further to ensure that there was no marginal improvement which the patient might have thought irrelevant. If there was none, do not discredit the patient's report, but try alternative techniques until there is a positive response. The patient must understand that what the therapist is seeking is not gratification but the truth.

\section{ASSESSMENT BASED ON T.P.P.}

When attempting to get a numerical estimate of a pain syndrome one must consider more than one parameter. Periodicity $(P)$, intensity $(I)$ and response to analgesics (R) are used according to the grading shown under the relevant headings.

Pain should be thought of in terms of "quantity of pain", i.e. how much pain is there for what proportion of the day, week, month, year? The quantity of pain is the sum of $P$ and $I$ and the indices for each of these are added together. It is not enough to estimate the severity of the syndrome in terms of intensity alone. If one adds the (R) index the numerical estimate has another dimension. The T.P.P. is the sum of the three indices, and an increase or decrease in any one of them will be reflected in a numerical reduction in T.P.P.

\section{Example}

A typical but uncomplicated pattern is depicted as follows:-

A woman, aged 53 complains of daily headache. She wakes without it but it comes on mid-morning and builds up. By midday it is so severe that she is unable to concentrate on her work as a typist.She is obliged to take two strong pain killers, which do not totally relieve her pain but reduce it to a level which allows her to continue her work through the afternoon.

\section{Estimate of her T.P.P. at this stage:}

$$
\mathbf{P}=4, \mathbf{I}=3, \mathbf{R}=4 \text {, T.P.P. }=11 \text {. }
$$

She says that she has suffered headaches for very many years, possibly since puberty, but that they have only been as bad as they are now for the past four years.

During her high school years she remembers having headaches at examination times but they were mild compared with her present headaches and were totally relieved by an aspirin.

\section{Estimate of her T.P.P. at that stage}

$$
\mathrm{P}=1, \mathrm{I}=1, \mathrm{R}=1 \text {, T.P.P. }=3 \text {. }
$$

After the birth of her second child (at age 23) the headaches became worse. She remembers when the children were small that she often had headaches which were no longer mild and aspirin had less and less effect.

\section{Estimate of T.P.P. over intervening years:}

$$
P=2 \ldots 3, I=2, R=2 \ldots 3 \text {, T.P.P. }=6 \ldots 8
$$

Four years ago, after a minor whiplash injury the headache worsened to its present level which has been established as

$$
\mathrm{P}=4, \mathrm{I}=3, \mathrm{R}=4 \text {. T.P.P. }=11
$$

After some initial treatment she reports that her headache came on as usual but went away for several hours after taking her usual tablets.

Now

$$
P .=4, I=3, R=3 . \text { T.P.P. }=10
$$

The therapist continues with the same treatment and the patient subsequently reports that her headache skipped a day, but when the pain came the following day it was of the same intensity, but was again totally relieved by the tablets.

Now

$P=3, I=3, R=3$. T.P.P. $=9$

Subsequent reports should reveal diminishing P, I and $R$ indices. When the patient has had no pain for a month.

$\mathrm{P}=$ ? O or $\mathrm{I}, \mathrm{I}=\mathrm{O}, \mathrm{R}=\mathrm{O}$, ie T.P.P. $=$ ? O or $\mathrm{I}$ This pattern may be graphically represented as shown in Diagram 2.

It is of critical importance to judge the initial marginal response to treatment. If this is not perceived or correctly interpreted the particular technique which produced this marginal improvement might not be pursued.

Furthermore, after the initial favourable response to treatment, there usually is an overall decline in the T.P.P. (and therefore of the syndrome) but it may not always be a linear decline. The improvement could be interspersed with peaks of seeming recurrences. If the therapist has an accurate record it will be clear to her, and to the patient, that these are peaks in a rapidly declining linear relationship (see Diagram 3). 


\section{T.P.P. HISTORY}
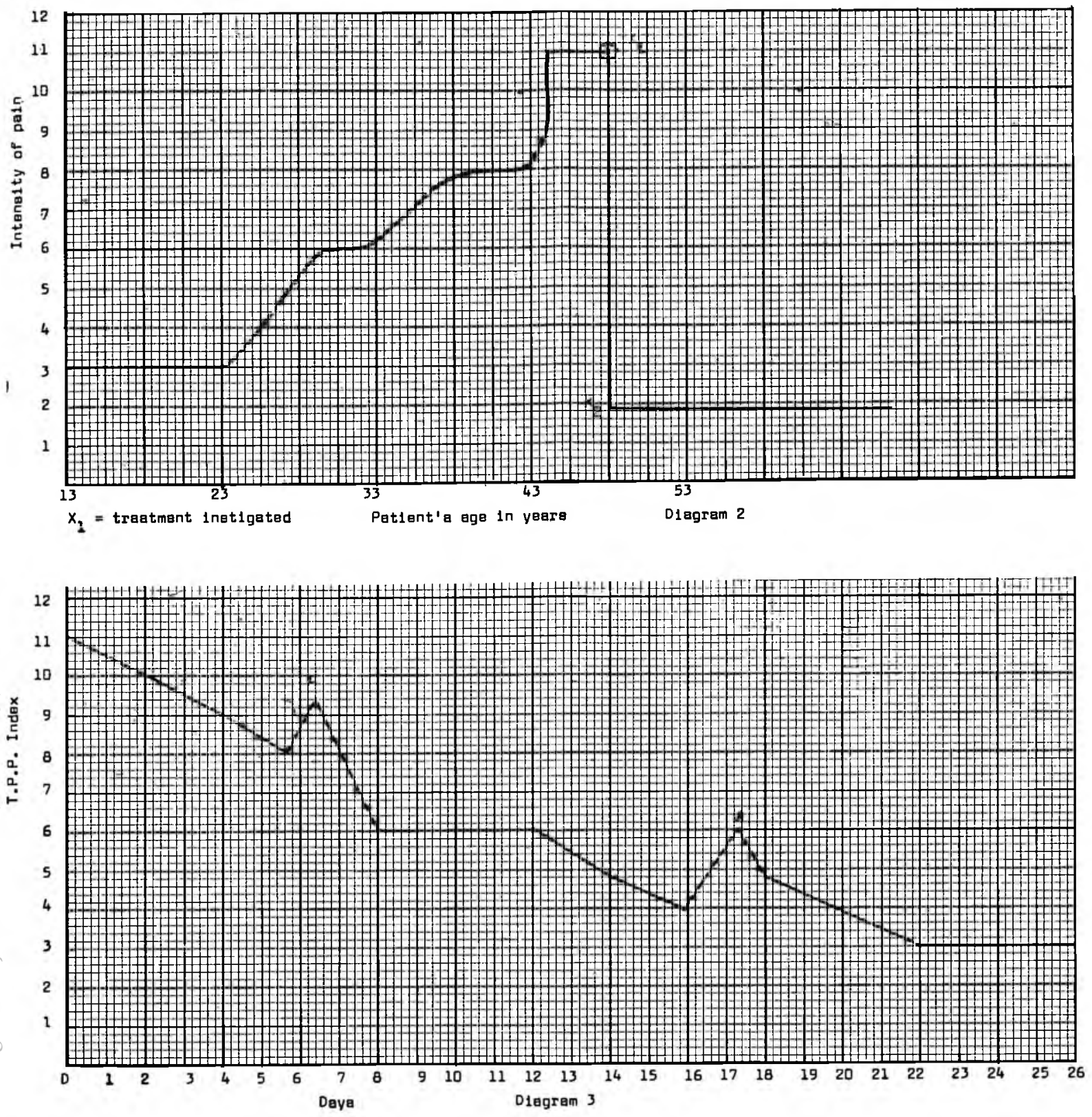

\section{CONCLUSION}

This system has served its purpose in over 700 cases of chronic headache assessed and treated over a period of eight years.

Although devised specifically for cervical headache most of it can be applied to other orthopaedic joint dysfunction and some of it possibly to other painful conditions which lie outside the author's experience.

\section{Refenences}

1. G. D. Maitland (1977) Vertebral Manipulation, 4th Ed London - Boston, Butterworths.

2. G. D. Maitland (1977) Peripheral Manipulation, 2nd
Ed., London - Boston, Butterworths.

3. Mitchell, D. (1979) Lecture notes on Pain.

\section{Bibliography}

De Caire, E (1970) Neurophysiology for Medical Graduates, Johannesburg, Witwatersrand University Press.

Ruch, T. C., Patton, H. D., Woodbury, J. W., Towe, A. L. (1965) Neurophysiology, 2nd Ed., Philadelphia and London, W. B. Saunders Company.

Koele, K. D., Smith, R. (1966): Discussion on research into pain. Section of General Practice of the Royal Society of Medicine. 